\title{
The anatomy of the anterior approach: a cadaver study
}

\author{
N Mogale, ${ }^{1}$ SAS Olorunju, ${ }^{2}$ S Matshidza, ${ }^{3} \mathrm{~N}$ Briers ${ }^{4}$
}

BMedSc(UFS), BSc(Macro Anat)(Hons)(UP), MSc(Anat)(UP), Lecturer: Department of Human Anatomy and Histology, Faculty of Health Sciences, Sefako Makgatho Health Sciences University, Pretoria, Ga-Rankuwa, South Africa; and Department of Anatomy, Faculty of Health Sciences, University of Pretoria, Pretoria, South Africa

2 BSc(Hons) Stats (Ahmadu Bello University, Nigeria); MSc (Applied Statistics) (UKC United Kingdom); PhD (Ahmadu Bello University, Nigeria), Statistician, Biostatistics Unit, Medical Research Council, Pretoria, South Africa

3 MBChB(Medunsa), MMed(Ortho)(Medunsa), Consultant and Head of Department of Orthopaedics, University of the Free State, Bloemfontein, South Africa; and Universitas Hospital, Bloemfontein, South Africa

4 BSc(SU), BScHons(Physiology)(UP), MSc(Physiology)(UP), DHETP(UP), PhD(Anat)(UP), PGDip(Health ResEth)(SU), Senior Lecturer, Department of Anatomy, University of Pretoria, Pretoria, South Africa

Corresponding author: N Mogale, PO Box 94446, 0201 Boordfontein, Pretoria, Cell: 072543 1458, Tel: 012521 4504, Email: nkhensani1909@gmail.com

\begin{abstract}
Background: This research investigated the anatomy underlying minimally invasive total hip arthroplasty when the anterior approach was used.

Methods: Ninety hips were dissected and in one cadaver, a complete hip replacement was performed. Simulations of the anterior approach surgical incisions were carried by the orthopaedic surgeon in order to see if injury to the lateral femoral cutaneous nerve (LFCN) could be avoided, when the correct anatomical landmarks were palpated.

Results: The data analysis revealed significant differences for the mean distances from the pubic tubercle to the straight head of the rectus femoris muscle. Statistical significance was detected for comparisons between males and females, for weight ranges and BMI categories.

Conclusion: The study findings prove that the concerns relating to the course and distribution pattern of the LFCN and the lateral circumflex femoral artery (LCFA) using the anterior approach, could be overcome when the anatomy of the hip joint and the thigh is understood. However, it is important to note the possible variations in the course of the LFCN and the branching pattern of the LCFA in order to avoid intra-operative bleeding and possible thigh numbness post-surgery.
\end{abstract}

Key words: lateral circumflex femoral artery (LCFA), lateral femoral cutaneous nerve (LFCN), anterior approach, femoral artery, hip arthroplasty

Citation: Mogale N, Olorunju SAS, Matshidza S, Briers N. The anatomy of the anterior approach: A cadaver study. SAOJ 2017;16(3):35-40. DOI 10.17159/2309-8309/2017/v16n3a4

Editor: Prof Anton Schepers, University of the Witwatersrand

Received: September 2016 Accepted: April 2017 Published: August 2017

Copyright: @ 2017 Mogale N, et al. This is an open-access article distributed under the terms of the Creative Commons Attribution Licence, which permits unrestricted use, distribution and reproduction in any medium, provided the original author and source are credited.

Funding: No funding was received for the writing of this article.

Conflict of interest: The authors declare that they have no financial or personal relationship(s) which may have inappropriately influence them in writing this article. The content of this article is the original work of the authors.

\section{Introduction}

The history of hip arthroplasty dates back to the 1700s when the foundation for the various methods used was laid by Henry Park (1744-1831). ${ }^{1}$ The evolution has seen the introduction of new methods and contention over concepts such as the incision length necessary for the surgical procedure. ${ }^{2-5}$ Different authors are, however, in agreement that the purpose of hip arthroplasty is to produce a painless, freely mobile and stable joint and for the patient to return to function post surgery. ${ }^{4-10}$

The direct anterior approach was initially described by Hueter (1885), who looked through the interval between the tensor fascia latae (TFL) and rectus femoris; this technique has been suggested as being superior to the other available anterior approach techniques. ${ }^{7,11}$ 
Several approaches and methods have been investigated by authors such as Keggi and Grey $(2005)^{6}$ and Bal (2008). ${ }^{4}$ These different methods all have the objective of finding a technique that causes the least structural damage, but allows the greatest access to the acetabulum for the placement of the acetabula component. ${ }^{4}$ As part of the emphasis on reduced surgical trauma in total hip arthroplasty (THA), utilisation of the direct anterior approach through the interval between the TFL and rectus femoris has been promoted. ${ }^{7}$ This approach is advised by certain surgeons, as the dissection is entirely within intermuscular planes. ${ }^{2,6,12-14}$

The anterior approach to hip arthroplasty has transformed from the use of the Hueter technique to the now popular Smith-Petersen technique. The Smith-Petersen approach is advised by some surgeons as the dissection is entirely within intermuscular planes. ${ }^{2,6,12-15}$ The Hueter technique entails a surgical procedure performed with the patient in a supine position. The incision is made vertically, extending about $15 \mathrm{~cm}$ down from the anterior superior iliac spine (ASIS), passing between the sartorius and the TFL muscles. The incision is extended laterally to the rectus femoris muscle and down to the anterior capsule of the hip joint, which is later exposed by blunt dissection. ${ }^{11,16}$ The Smith-Petersen technique is similar in that it uses the area between the fascia of the sartorius and TFL muscles to access the hip joint. ${ }^{17,18}$

The use of the anterior approach to hip arthroplasty does, however, pose concerns for surgeons. These relate to difficulty experienced when placing the femoral component, and possible injury to the LFCN $^{12}$ and the ascending branch of LCFA is valid. Various authors agree that injury to the LFCN during surgery could lead to possible thigh numbness post surgery. 2,4,12,15 The current study investigated the anatomy underlying the anterior approach while aiming to address concerns relating to the LCFA and the LFCN when the anterior approach to hip arthroplasty was used. In addition, variations in the branching pattern and course of the LCFA and the LFCN were noted as these have direct bearing on post-surgical complications.

\section{Materials and methods}

In the attempt to describe a standard method for the anterior approach performed on the cadaver, a pilot study was conducted. The pilot study was also meant to find the agreement rating between two different dissectors.

A simulation of the anterior approach to hip surgery was performed on cadaver material by the orthopaedic surgeon. The incision and transecting of the muscles were performed by the primary investigator. The advantage of using cadaver material was that it enabled the expansion of the exploratory incision by the primary investigator. As a result, the joint could be exposed and the LFCN could be visualised along with the distribution of its branches (Figures 1a and 1b). The sartorius muscle and the rectus femoris muscle could also be transected for better access to the hip joint. In living persons however, the muscles are retracted; this is not possible when using cadaver material due to its fixed and hardened state. From the pilot study, we gathered that the data for the anterior approach would be collected with the cadaver in a supine position. The iliac crest, pubic tubercle, anterior superior iliac spine (ASIS), medial condyle, lateral condyle and other anatomical landmarks, were easily palpable (Figure 1a).

Three incisions were made, as represented in Figures $1 \mathrm{a}$ and $1 \mathrm{~b}$. First, an incision was made from a point about $2 \mathrm{~cm}$ lateral and $1 \mathrm{~cm}$ superior to the ASIS. This incision extended from the area around the ASIS to the pubic tubercle in undissected cadavers. The incision allowed for the exposure of the inguinal ligament. This was important for identifying the LFCN as it becomes visible inferior to the inguinal ligament. Secondly, an imaginary line was drawn from a point $2 \mathrm{~cm}$ lateral to the ASIS along the skin overlying the TFL muscle, to the lateral condyle of the femur. A second incision was then made along this line.
The last incision was made from the lateral condyle to the medial condyle of the femur, with the intention of fully exposing the quadriceps femoris muscle and studying the distribution of the branches of LFCN. It is important for the orthopaedic surgeon to be aware of these branches, their course and variations in their branching, as injury to the LFCN branches may cause thigh numbness post surgery. 4,19,20 The LFCN exits the pelvis and then sends branches medially across the sartorius muscle, 2 to $3 \mathrm{~cm}$ distal to the ASIS. ${ }^{21}$ For the purpose of this study, it is necessary to identify the inguinal ligament, as the LFCN passes deep to the inguinal ligament before it can be identified over the sartorius muscle (Figure 1b).

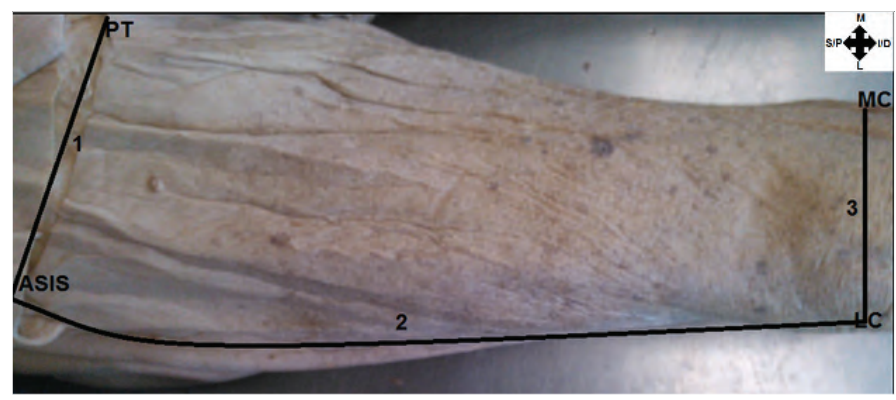

Figure 1a. Anterior view of the thigh showing the imaginary lines along which the incisions were made. The first incision (1) was made from the PT to the ASIS; the second incision (2) was made on a line connecting ASIS to the LC. The last incision (3) was made from the LC to MC.

Key: I-Inferior; D-Distal; M-Medial; L-Lateral; S-Superior; P-Proximal; A-Anterior; P-Posterior; PT-Pubic tubercle; MC-Medial condyle of the femur; LC-Lateral condyle of the femur

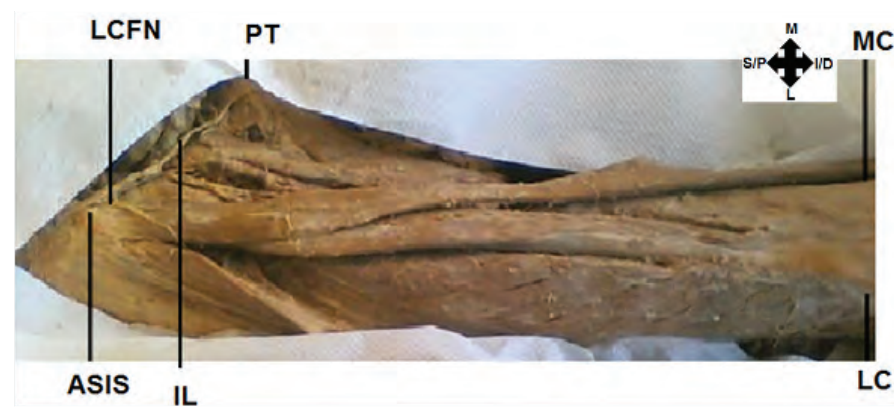

Figure 1b. Anterior view of the thigh showing the anatomical landmarks to be palpated before the skin is reflected. These include the pubic tubercle, medial condyle, lateral condyle and the ASIS.

Key: I-Inferior; D-Distal; M-Medial; L-Lateral; S-Superior; P-Proximal; PT-Pubic tubercle; MC-Medial condyle of the femur; LC-Lateral condyle of the femur; IL-Inguinal ligament

The skin overlying the ASIS and part of the iliac crest, TFL muscle and the LFCN were carefully dissected and reflected medially, to expose the subcutaneous fat and superficial vessels. It was noted that if the orthopaedic surgeon accessed the anterior capsule of the hip joint in the manner described in current literature, ${ }^{2,18}$ no other major vessels (such as the ascending branch of the LCFA) would be injured as these are clearly visible and can easily be avoided. Any variations of the normal regional anatomy were also noted.

The subcutaneous fat was removed until the thin, translucent fascia overlying the TFL muscle was exposed. The fascia was then teased out using a finger to isolate the TFL laterally, slipping into the interval between the superior femoral neck and the abductors. ${ }^{2}$ The TFL muscle was identified and split along its anterior margin to expose the LFCN and trace it back to its relation to ASIS and the inguinal ligament. 
The nerve, along with its branches, was identified in its course as it passes behind the inguinal ligament and becomes visible medial to the ASIS. The branches were followed and dissected out before the fascia was cleaned, so as not to damage the LFCN before exposing the underlying muscles. The course and number of branches were noted as they remain an area of concern for injury during hip arthroplasty.

The subcutaneous fat was then dissected more medially until the translucent fascia overlying the sartorius muscle and the quadriceps femoris muscle was clearly visible. The fascia was then dissected and the sartorius muscle and the quadriceps femoris muscle separated by blunt dissection to expose the LCFA (I). The sartorius muscle $(\mathrm{J})$ was transected (Figure 2a). This allowed better access to the anterior capsule of the hip joint and the LCFA. The rectus femoris muscle $(\mathrm{K})$ was transected and its straight head elevated from the underlying capsule by blunt or sharp dissection.

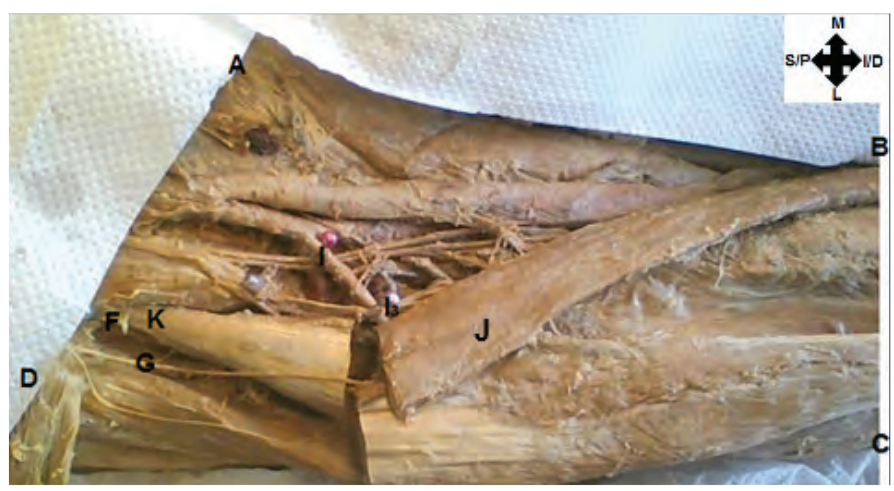

Figure 2a. A deeper dissection of the anterior compartment of the thigh showing the reflected head of rectus femoris and sartorius muscles along with the tensor fascia latae muscle with the iliotibial band removed. The lateral circumflex femoral artery (I) is clearly visible.

Key: I-Inferior; D-Distal; M-Medial; L-Lateral; S-Superior; P-Proximal

The surgical method used when applying the anterior approach to THA can be done through a short incision. It is possible to extend it distally along the femur, or along the anterior iliac crest. This incision is usually as short as possible but as long as necessary. The results of the anterior approach are not affected by a slightly longer skin incision but can be compromised by unnecessarily short incisions. ${ }^{14}$ The cadaver incision however, is made longer to allow for clear visualisation of the TFL, the LFCN, the LCFA as well as easy access to the anterior capsule of the hip joint. Coloured pins were used to mark various anatomical landmarks and distances measured from the following points (Figure 2b):

The distances measured were from the pubic tubercle $(A)$ to the anterior capsule of the hip joint $(F)$ and the shortest distance from the pubic tubercle $(A)$ to the LFCN $(G)$. The distance from the pubic tubercle (A) to the LCFA (I) was measured along with the shortest distance from the ASIS (D) to the LFCN (G). The shortest distance from the anterior capsule of the hip joint (F) to the LFCN $(G)$, the distance from the anterior capsule of the hip joint (F) to the LCFA (I) and the distance from the anterior capsule of the hip joint $(F)$ to where the LCFA $\left(I_{3}\right)$ branches into the ascending and descending branches were measured. Other measurements included the distance from the pubic tubercle (A) to the medial boundary of the head of the rectus femoris muscle $(K)$; the distance from where the femoral artery is first visualised exiting behind the inguinal ligament to where it gives off the deep artery of the thigh; the distance from where the deep artery of the thigh gives off the LCFA (I); the distance from the origin of the LCFA (I) from the deep artery of the thigh, to where it gives off an ascending, descending and/or transverse branch; and lastly, the distance from LCFA (I) branching into ascending, descending and/or transverse branch to where the ascending and/or descending gives off a transverse branch.

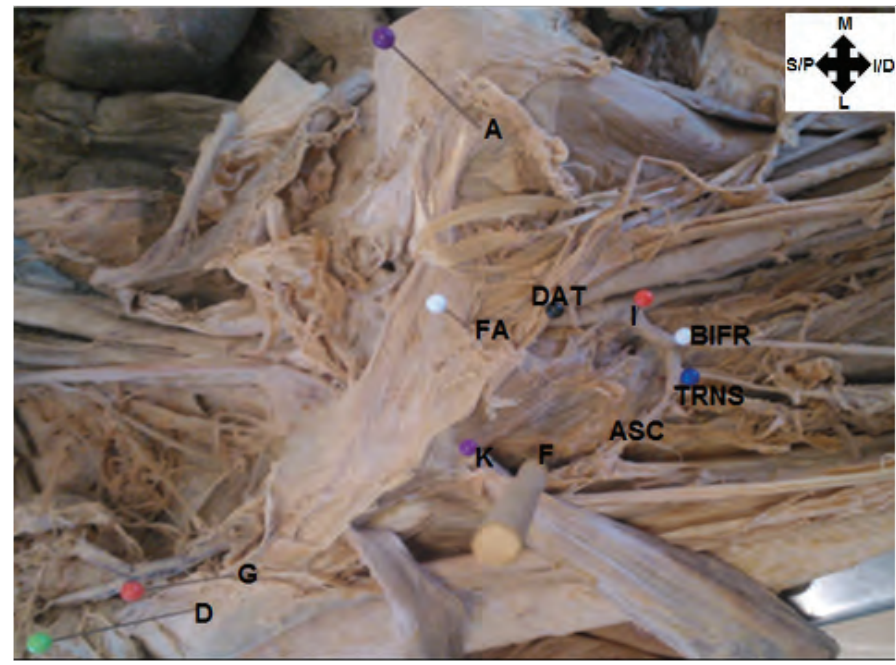

Figure 2b. A deeper dissection of the anterior compartment of the thigh showing the distances measured in relation to the pubic tubercle, ASIS, LCFA, LFCN and the anterior capsule of the hip joint.

Key: I-Inferior; D-Distal; M-Medial; L-Lateral; S-Superior; P-Proximal

\section{Orthopaedic simulation}

One of the factors that account for the reluctance of orthopaedic surgeons to adopt the anterior approach to hip arthroplasty is the high learning curve for the anterior approach. The complications that may arise if the high learning curve is not overcome is the possibility of thigh numbness if the LFCN or any of its branches are cut. ${ }^{19,20}$ Death could also result if the LCFA is severed. 6,8 In the attempt to demonstrate the possible ease of performing hip arthroplasty using the anterior approach, it was necessary to request the assistance of a surgeon with experience in both the anterior and the anterolateral approach.

The orthopaedic surgeon therefore, simulated the anterior approach surgical procedure on the cadaver by first palpating all the relevant anatomical landmarks before making the necessary incisions. ${ }^{17,18,22}$ In this regard, 21 hips were first marked with pins, incisions made and the area around the incision dissected to assess 'the level of damage,' if any, to the LFCN (Figures 3 and 4).

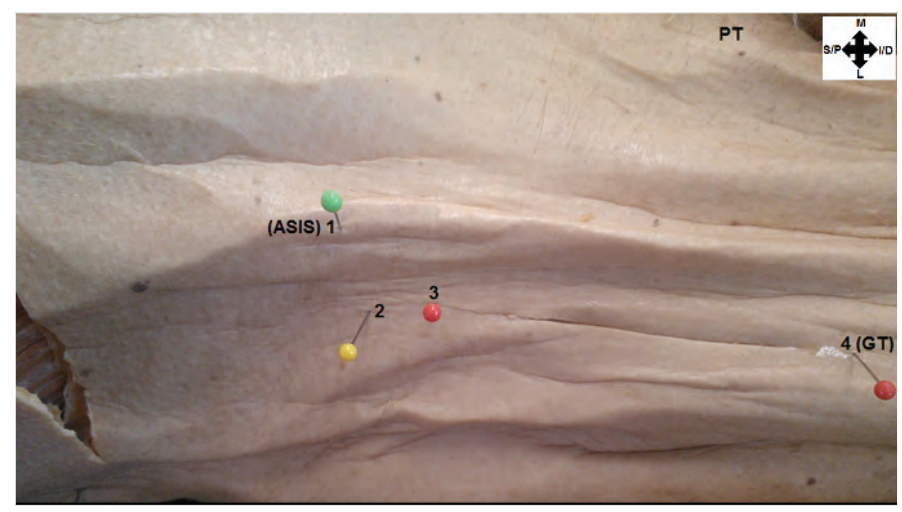

Figure 3. A Lateral view of the thigh with the cadaver in the supine position. Pins are inserted to indicate anatomical landmarks. The first pin (1) is inserted on the ASIS; the second and third pins, $2 \mathrm{~cm}$ lateral (2) and inferior (3) to ASIS; and the fourth (4) $2 \mathrm{~cm}$ medial to the greater trochanter. Key: I-Inferior; D-Distal; M-Medial; L-Lateral; S-Superior, P-Proximal; PT-Pubic tubercle; GT-Greater trochanter 
The cadavers were all in the supine position, and the following landmarks palpated: ASIS, greater trochanter of the femur and most lateral aspect of the patella. The orthopaedic surgeon's incision was then made $2 \mathrm{~cm}$ lateral and $2 \mathrm{~cm}$ inferior to the ASIS. This is important in avoiding possible damage to the LFCN which is sometimes found running on the ASIS after exiting posterior to the inguinal ligament en route to innervate the thigh. The first pin was inserted on the ASIS, the second was $2 \mathrm{~cm}$ lateral and inferior to ASIS, the third $2 \mathrm{~cm}$ medial to the greater trochanter and the fourth pin on the greater trochanter. The incision was made in the area between the second and third pins (Figure 3). This incision in live patients can be as small as $5 \mathrm{~cm}$ but is usually $8-10 \mathrm{~cm}$ long., ${ }^{9,23-25}$ The skin around the incision was reflected medially and laterally and the LFCN, along with its branches, dissected out (Figure 4).

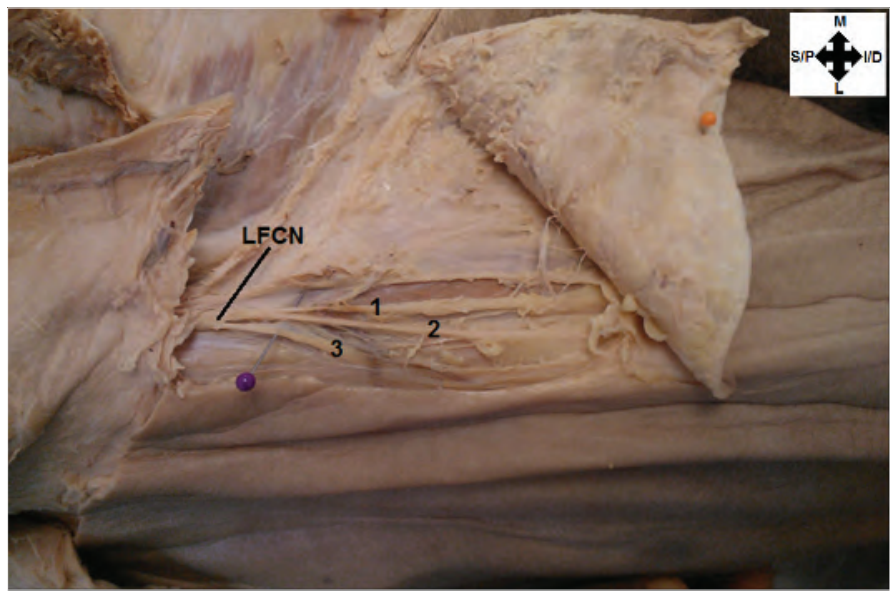

Figure 4. Anterolateral view of the thigh with the cadaver in the supine position. The nerve (LFCN) and all its branches (1, 2 and 3) are still intact after dissecting the area around the incision.

Key: I-Inferior; D-Distal; M-Medial; L-Lateral; S-Superior; P-Proximal; A-Anterior; P-Posterior

\section{Results}

Standard descriptive statistics (including means, standard error, 95\% Cl) were calculated per age group, sex, BMl, height and weight ranges. An analysis of variance (ANOVA) was used to assess differences in measurements from the various anatomical landmarks to the soft tissue between different age groups, sexes, BMl ranges, height and weight ranges. Results from the current study were compared to results from other studies regarding distance from the various anatomical landmarks to the soft tissue discussed.

The findings made in the study include comparisons per age differences, sex, weight ranges and BMI. The findings made are clearly documented in Tables $I-V$. For the age comparisons, significant differences were detected on the left side for samples younger than 50 years of age and those older than 50 years. These findings documented in Table / present the distances from the pubic tubercle to the LCFA, and from the pubic tubercle to the straight head of the rectus femoris muscle. Significant differences for sex comparisons were detected on both the left and the right side. The left side measurements were detected for mean distances from the pubic tubercle to the anterior capsule of the hip joint (Table II). The right-side measurements were detected from the pubic tubercle to the straight head of the rectus femoris and from the ascending branch of the LCFA to where it gives off a transverse branch of the LCFA (Table III). Significant differences for weight comparisons were detected on the right side for distances measured from the ascending branch of the LCFA to where it gives off a transverse branch (Table $M$ ). The last significance in measurements was detected for $\mathrm{BMl}$ ranges, for distances from the anterior capsule of the hip joint to the branching of the LCFA from the deep artery of the thigh or directly from the femoral artery (Table $V$ ). This significant difference was detected for ANOVA comparison with LSD for BMl ranges of $18-25 \mathrm{~kg} / \mathrm{m}^{2}$ and $25.1-30 \mathrm{~kg} / \mathrm{m}^{2}$.

Table I: Left side measurements in a sample of ages $<50$ years and $\geq 50$ years

\begin{tabular}{|c|c|c|c|c|c|c|c|c|}
\hline Landmark & Group & $\mathbf{N}$ & Mean & SE & \multicolumn{2}{|c|}{$95 \%$ Confidence interval } & $\begin{array}{l}\text { t-test, } \\
\text { p-value }\end{array}$ & $\begin{array}{l}\text { Difference in } \mathrm{mm} \\
(<50 \text { minus } \geq 50)\end{array}$ \\
\hline \multirow{3}{*}{$A-1$} & $<50$ & 13 & 62.15 & 3.45 & 53.64 & 68.67 & \multirow{3}{*}{0.01} & \multirow{3}{*}{-9.75} \\
\hline & $\geq 50$ & 31 & 70.90 & 1.55 & 67.73 & 74.07 & & \\
\hline & Total & 44 & 68.02 & 1.62 & 64.75 & 71.29 & & \\
\hline \multirow{3}{*}{ A-K } & $<50$ & 13 & 77.31 & 3.31 & 70.10 & 84.51 & \multirow{3}{*}{0.05} & \multirow{3}{*}{-6.89} \\
\hline & $\geq 50$ & 31 & 84.19 & 1.66 & 80.81 & 87.58 & & \\
\hline & Total & 44 & 82.16 & 1.58 & 78.98 & 85.34 & & \\
\hline
\end{tabular}

Significant differences between groups are highlighted (t-test, $p \leq 0.05$ )

Table II: Left side measurements in a sample comparing sex (males and females)

\begin{tabular}{|c|c|c|c|c|c|c|c|c|}
\hline Landmark & Group & $\mathbf{N}$ & Mean & SE & $95 \%$ Cor & e interval & $\begin{array}{l}\text { t-test, } \\
\text { p-value }\end{array}$ & $\begin{array}{l}\text { Difference in } \mathrm{mm} \\
(<50 \text { minus } \geq 50)\end{array}$ \\
\hline \multirow{3}{*}{$A-F$} & Males & 37 & 86.95 & 1.69 & 83.51 & 90.38 & \multirow{3}{*}{0.04} & \multirow{3}{*}{12.07} \\
\hline & Females & 8 & 74.88 & 3.66 & 66.23 & 83.52 & & \\
\hline & Total & 45 & 84.80 & 1.67 & 81.43 & 88.17 & & \\
\hline
\end{tabular}

Significant differences between groups are highlighted (t-test, $p \leq 0.05$ ) 
Table III: Right side measurements in a sample comparing sex (males and females)

\begin{tabular}{|c|c|c|c|c|c|c|c|c|}
\hline Landmark & Group & $\mathbf{N}$ & Mean & SE & \multicolumn{2}{|c|}{$95 \%$ Confidence interval } & $\begin{array}{l}\text { t-test, } \\
\text { p-value }\end{array}$ & $\begin{array}{l}\text { Difference in } \mathrm{mm} \\
(<50 \text { minus } \geq 50)\end{array}$ \\
\hline \multirow{3}{*}{$A-K$} & Males & 35 & 85.60 & 1.63 & 82.28 & 88.92 & \multirow{3}{*}{0.02} & \multirow{3}{*}{8.16} \\
\hline & Females & 9 & 77.44 & 1.73 & 73.45 & 81.44 & & \\
\hline & Total & 44 & 83.93 & 1.42 & 81.05 & 86.81 & & \\
\hline \multirow{3}{*}{ ASC-TRNS } & Males & 23 & 14.96 & 1.66 & 11.52 & 18.40 & \multirow{3}{*}{0.04} & \multirow{3}{*}{6.33} \\
\hline & Females & 8 & 8.63 & 1.18 & 5.84 & 11.41 & & \\
\hline & Total & 31 & 13.32 & 1.36 & 10.55 & 16.09 & & \\
\hline
\end{tabular}

Significant differences between groups are highlighted (t-test, $p \leq 0.05)$

Table IV: Right side measurements in a sample comparing individuals of different weight ranges for p-values using ANOVA

\begin{tabular}{|c|c|c|c|c|c|c|c|}
\hline Landmark & Group & $\mathbf{N}$ & Mean & SE & \multicolumn{2}{|c|}{$95 \%$ Confidence interval } & $\begin{array}{l}\text { ANOVA, } \\
\text { p-value }\end{array}$ \\
\hline \multirow{4}{*}{ ASC-TRNS } & $<50$ & 9 & 13.56 & 2.56 & 7.66 & 19.45 & \multirow{4}{*}{0.02} \\
\hline & $<100$ & 13 & 13.62 & 1.75 & 9.81 & 17.43 & \\
\hline & $>100$ & 1 & 36.00 & & & & \\
\hline & Total & 23 & 14.57 & 1.68 & 11.08 & 18.05 & \\
\hline
\end{tabular}

Significant differences between groups are highlighted (ANOVA $p \leq 0.05$ )

Table V: Left side measurements of $p$-values comparison of ANOVA with LSD for the sample of different BMI ranges

\begin{tabular}{|l|c|c|c|cc|}
\hline Landmark & BMI & $<18$ & $18-25$ & $25.1-30$ & $>30$ \\
\hline \multirow{2}{*}{$\mathrm{F}-\mathrm{I}_{3}$} & $<18$ & $\mathrm{X}$ & 0.32 & 0.23 & 0.31 \\
\hline & $18-25$ & 0.32 & $\mathrm{X}$ & $\mathbf{0 . 0 5}$ & 0.11 \\
\hline & $25.1-30$ & 0.23 & 0.05 & $\mathrm{X}$ & 0.94 \\
\hline & $>30$ & 0.31 & 0.11 & 0.94 & $\mathrm{X}$ \\
\hline
\end{tabular}

Significant differences between groups are highlighted (ANOVA, $p \leq 0.05$ )

\section{Discussion}

The current study revealed the measurements for the distances from the pubic tubercle to the LCFA to be significant for left-side measurements. Therefore, caution must be exercised when using the pubic tubercle as an anatomical landmark in the attempt to determine the location of the LCFA, as the distances of the LCFA in relation to the pubic tubercle may vary. The LCFA was measured at the point where it is branching from the deep artery of the thigh or from the femoral artery. In the current study, we found the LCFA branching from the deep artery of the thigh in 74/90 (82.2\%) of the hips dissected. These findings compare well with findings made by Massoud and Fletcher, and Prakash et al. who found this percentage to be $81 \%$ and $81.25 \%$, respectively. ${ }^{26,27}$ In the remaining $16 / 90$ (17.8\%) hips, the LCFA branched directly from the femoral artery. Previous literature examining the origin of the LCFA omits the distance from the LCFA in relation to the ASIS or the pubic tubercle. The implications of attempting to use the pubic tubercle as a landmark for locating the LCFA could result in vascular injuries during THA procedures.

We noted that in 59/90 (65.6\%) cases, the transverse branch branched from ascending branch of LCFA while in 9/90 (10\%) hips dissected, the transverse branch branched from the descending branch of the LCFA. Our results also showed that the transverse branch of the LCFA was not always visible as was the case is 4/90 (4.4\%) hips dissected, where no transverse branch of the LCFA was found. In the literature reviewed regarding the origin of the LCFA and its variations, no study could be found that investigated the distance from the ascending/descending branch of the LCFA to the branching of the ascending/descending branch into an ascending/ descending branch and a transverse branch. The origin of the transverse branch of the LCFA has also not been investigated by previous studies, creating a challenge in the attempt to compare the current study to previous research.

In the category comparing individuals of varying BMl ranges, significant differences were detected in the sample of individuals in the $\mathrm{BMl}$ ranges between 18 and $25 \mathrm{~kg} / \mathrm{m}^{2}$ and those individuals with $\mathrm{BMI}$ higher than $25 \mathrm{~kg} / \mathrm{m}^{2}$ but equal to and not higher than $30 \mathrm{~kg} / \mathrm{m}^{2}$. These significant differences were the left side measurements for distances from the anterior capsule of the hip joint to the branching of the LCFA (from the deep artery of the thigh/the femoral artery). The current study revealed the branching of the LCFA from the deep artery of the thigh to be apparent in 74/90 (82.2\%) of the hips dissected. In their case report study, Balachandra et al. found the origin of the LCFA to be the deep artery of the thigh and to a lesser degree the femoral artery, which is comparable to previous studies. ${ }^{28}$ The study is consistent with the findings made by Dixit et al., Choi et al. and Prakash et al. 27,29,30 In the findings by Dixit et al., the LCFA was found branching from the deep artery of the thigh in $83.34 \%$ in their study cases. Choi et al. and Prakash et al. found this percentage to be $86.8 \%$ and $81.25 \%$, respectively. In 16/90 (17.8\%), the LCFA branched from the femoral artery. These findings are comparable with the study by Balachandra et al. (2011). ${ }^{28}$ Similar findings were made by Dixit et al., who found this to be the case in $16.66 \%$ of their study sample. ${ }^{29}$ Choi et al. found this percentage to be slightly lower, at $13.2 \%$ in their study. ${ }^{30}$ In the study by Üzel et al. this percentage stands at $22.7 \% .{ }^{20}$ The current study compares closely with the findings by Prakash et al. who found this average to be $18.75 \%$ in their study sample. ${ }^{27}$

The average distance from the ASIS to the LFCN was noted as $13.6 \mathrm{~mm}$ on the left side and $12.6 \mathrm{~mm}$ on the right side of the total hips dissected. The measurement of the LFCN in relation to the ASIS was taken at the point where the LFCN courses posterior to the inguinal ligament, as no interruption to the original location of the nerve had occurred at the point. Ray et al. found the LFCN to course $25 \mathrm{~mm}$ medially from the ASIS in $72 \%$ of their study cases. ${ }^{19}$ The findings made in this study relate closely to those of Mischkowski et al.; in their study, the average distance from the ASIS to the point where the nerve courses posterior to the inguinal ligament was found to be $14.99 \mathrm{~mm}^{31}$ 
The LFCN is formed from the L2-L3 posterior rami and courses over the iliacus muscle in the false pelvis. The LFCN exits the abdomen by traversing posterior to the inguinal ligament, coursing on the medial aspect of the ASIS. ${ }^{32}$ The LFCN, as seen in the anterior compartment of the thigh, crosses the sartorius muscle between the TFL muscle and the iliacus fascia..$^{19,21}$ The LFCN provides cutaneous innervation to the lateral and anterolateral aspect of the thigh; thus, injury to the LFCN may result in thigh numbness post surgery. ${ }^{4}$ Variations in the anatomy and the branching pattern of the LFCN were noted in previous studies. Ray et al. (2010) found the LFCN to course $25 \mathrm{~mm}$ medially from the ASIS in $72 \%$ of their study cases. ${ }^{19}$ The current study found the course of the LFCN to be an average of $13.6 \mathrm{~mm}$ from the ASIS on the left side in 40/45 (89\%) hips dissected and $12.6 \mathrm{~mm}$ from the ASIS on the right side in $45 / 45$ hips dissected. Other studies have also reported the course of the LFCN to cross lateral to the ASIS; these ranges were found to be between $0 \%$ and $19 \% .{ }^{19,31}$ The current study revealed that none of the LFCNs were found running on the lateral aspect of the ASIS; however, in 5/45 (11\%) hips dissected on the left side, the LFCN was found coursing directly over the ASIS.

\section{Limitations}

During the data collection phase of the study, several limitations were encountered. The methods used for the data collection of this study were mainly to accommodate the fixed and hardened nature of cadaver tissue. Difficulty was encountered in palpation of the various anatomical landmarks prior to incising the skin; this difficulty is a result of the hardened cadaver tissue. Cadaver material is a scarce resource and as a result the data collection was also restricted by the limited number of cadavers.

\section{Conclusion}

In the study, it was noted in that $15.6 \%$ of the cases the LCFA had four branches, and $11.1 \%$ of the cases the LCFA had five branches. As many as six branches of the LCFA could be found and this was seen in $3.3 \%$ of the study sample.

The ascending branch of the LCFA is an area of concern for orthopaedic surgeons using the anterior approach; this is supported in the study, and our findings revealed that in $65.6 \%$ of the study sample the ascending branch of the LCFA gave rise to the transverse branch. Ligation of the ascending branch of the LCFA during hip arthroplasty would therefore require caution. In $1 \%$ of the sample, the ascending branch was noted to be branching directly from the femoral artery while the transverse and descending branches of LCFA originated from the deep artery of the thigh. Variations in the origin of the LCFA were also noted in the study, with $17.8 \%$ originating directly from the femoral artery.

The LFCN was noted to be coursing directly over the ASIS in 11\% of the study sample. The average distance of the LFCN from the ASIS was noted as $13.6 \mathrm{~mm}$ on the left side and $12.6 \mathrm{~mm}$ on the right side. It is of clinical significance that the orthopaedic surgeon performing surgery using the anterior approach is aware of variations in the branching pattern of the LCFA, to avoid complications and possible intra-operative bleeding.

\section{Compliance with ethics guidelines}

Ethical clearance for this study was obtained (Protocol number: 274/2014) prior to the commencement of the data collection phase of this study. All the adult cadavers used in this study were obtained and dissected under the rules and regulations defined within the South African National Health Act 61 of 2003. All data was collected from full body cadavers. The cadavers were handled with respect and care at all times, and properly safeguarded. No information which could possibly reveal the identities of the cadavers was obtained.

Access to personal information regarding the cadaver's age, height and weight was noted, and restricted to the author. No other personal information was obtained.

\section{References}

1. Park $\mathrm{H}$. An account of a new method of treating diseases of the joints of the knee and elbow. In: Pott MP, ed. London; 1782.

2. Kennon RE, Keggi JM, Keggi KJ. The anterior approach to hip arthroplasty: the short, single minimally invasive incision. Oper Techn Orthop 2004;14(2): 85-93.

3. Pour AE, Parvizi J, Rothman $\mathrm{RH}$. The outcomes of small-incision total hip arthroplasty using modifications of existing surgical approaches. Semin Arthro 2005; 16:194-97.

4. Bal BS. From two incisions to one: the technique of minimally invasive total hip arthroplasty with the anterior approach. Semin Arthro 2008:19:215-24.

5. Hozack W, Klatt BA. Minimally invasive two-incision total hip arthroplasty: is the second incision necessary? Semin Arthro 2008;19:205-208.

6. Keggi K, Grey M. Beyond minimally invasive total hip surgery with the anterior approach. Semin Arthro 2005;16:191-93.

7. Myers SR, Leahy M. Anterior approach total hip arthroplasty: the Heuter interval. Semin Arthro 2008;19:201-204.

8. Brown A, Matta J, Bal BS. Evolution and experience with minimally invasive anterior total hip arthroplasty performed on an orthopedic table. Semin Arthro 2008;19:209-14.

9. Duwelius PJ, Dorr LD. Current status of minimally invasive total hip arthroplasty: results to date. Semin Arthro 2007;18:262-67.

10. Moskal JT, Scanelli JA, Capps SG. Patient satisfaction after total hip arthroplasty comparing the direct anterior approach with other standard approaches. Surgery Curr Res 2014;4:174.

11. Heuter C. Die Verletzungen und Krankheiten des Hufgegend und der oberen Halfte des Oberschenkels. In: Grundriss der Chirurgie, Edited. F.C.W.Vogel, Leipzig;pp 125-95.

12. Trousdale RT. Anterior surgical approaches for hip arthroplasty. Semin Artho 2004; 15:76-78.

13. Mattingly DA. Surgical exposures for primary total hip arthroplasty. Oper Techn Orthop 1995;5(4):311-15.

14. Keggi KJ; Rubin LE. Total hip arthroplasty with the anterior surgical approach using one or two incisions. Semin Arthro 2008;19:175-79.

15. Petis S, Howard JL, Lanting BL, Vasarhelyi EM. Surgical approach in primary total hip arthroplasty: anatomy, technique and clinical outcomes. J Can Chir 2015:58(2):128-39.

16. Judet J, Judet R. The use of an artificial femoral head for arthroplasty of the hip joint. J Bone Joint Surg 1950;32B(2):166-73.

17. Smith-Petersen MN. Approach to and exposure of the hip joint for mold arthroplasty. J Bone Joint Surg Am 1949;31A:40-46.

18. Lovell TP. Single-incision direct anterior approach for total hip arthroplasty using a standard operating table. J Arthro 2008;23(7):64-68.

19. Ray B, d'Souza AS, Kumar B, Marx C, Ghosh B, Gupta NK, Marx A. Variations in the course and microanatomical study of the lateral femoral cutaneous nerve and its clinical importance. Clinical Anatomy 2010;23:978-84.

20. Üzel M, Akkin SM, Tanyeli E, Koebke J. Relationships of the lateral femoral cutaneous nerve to bony landmarks. Clin Orthop Relat Res 2011;469:2605-11.

21. Moore KL, Dalley AF. Clinically oriented anatomy. Philadelphia: Lippincott Williams \& Wilkins; 1999:530-33,45.

22. Smith-Petersen MN. A new supra-articular subperiosteal approach to the hip joint. Am J Orthop Surg 1917;15:592-95.

23. Sariali E, Leonard P, Mamoudy P. Dislocation after total hip arthroplasty using heuter anterior approach. J Arthro 2008;23(2):266-72.

24. Mast NH, Laude F. Revision total hip arthroplasty performed through the heuter interval. J Bone Joint Surg Am 2011;93(2):143-48.

25. Werner BC, Brown TE. Instability after total hip arthroplasty. World J Orthop 2012;3(8):122-30.

26. Massoud TF, Fletcher EWL. Anatomical variants of the profunda femoris artery: an angiographic study. Surg Radiol Anat 1997;99-103.

27. Prakash, Kumari J, Bhardwaj AK, Jose BA, Yadav SK, Signh G. Variations in the origins of the profunda femoris, medial and lateral femoral circumflex arteries: a cadaver study in the Indian population. Rom J Morphol Embryol 2010;5(1):167-70.

28. Balachandra N, Prakash BS, Padmalatha K, Ramesh BR. Variation in the origin of the lateral circumflex femoral artery - a case report. Anatomica Karnataka 2011;5(1):76-80.

29. Dixit DP, Mehta LA, Kothari ML. Variations in the origin and course of profunda femoris. J Anat Soc India 2001;50(1):6-7.

30. Choi SW, Park JY, Hur MS, Park HD, Kang HJ, Hu KS, Kim HJ. An anatomic assessment on predators of the lateral circumflex femoral artery for anterolateral thigh flap. J Craniofac Surg 2007;18(4):866-71.

31. Mischkowski RA, Selbach I, Neugebauer J, Koebke J, Zoller JE. Lateral femoral cutaneous nerve and iliac bone grafts - anatomical and clinical considerations. Int J Oral Maxillofacial Surg 2006;35:366-72.

32. Carai A, Fenu G, Sechi E, Crotti FM, Montella A. Anatomical variability of the lateral femoral cutaneous nerve: findings from a surgical series. Clin Anat 2009;22: 365-70. 